Nine $(5 \%)$ and $48(6 \%)$ of ETA-B and ETA-O patients had stopped their respective treatments by the 1st FU. The adjusted hazard ratio for stopping ETA-O versus ETA-B over this time period was similar $(H R=0.8(0.4-1.6) ; p=0.5)$. Risk of SAEs over the first 6 months was also similar between groups (HR (ETA-B versus ETAO) $=0.6(0.3-1.1) ; p=0.1)$, with $10(6 \%)$ and $73(10 \%)$ SAEs reported in ETA-B and ETA-O patients respectively until 1 st FU.

Abstract AB0429 - Table 1

\begin{tabular}{|c|c|c|c|}
\hline Patients who are & Biological naive & \begin{tabular}{|l|} 
Switched from a \\
non-originator
\end{tabular} & $\begin{array}{l}\begin{array}{l}\text { Switched from } \\
\text { originator }\end{array} \\
\end{array}$ \\
\hline Number & 36 & 17 & 5 \\
\hline \multicolumn{4}{|l|}{ Biosimilar } \\
\hline Infliximab biosimilars & $28(77 \%)$ & $17(100 \%)$ & $3(60 \%)$ \\
\hline etanercept biosimilar & $8(22 \%)$ & $0(0 \%)$ & $2(40 \%)$ \\
\hline \multicolumn{4}{|c|}{\begin{tabular}{|l|l|} 
ILAR class & \\
\end{tabular}} \\
\hline Persistent Oligoarthritis & $4(11 \%)$ & $4(24 \%)$ & $0(0 \%)$ \\
\hline Extended Oligoarthritis & $8(22 \%)$ & $5(29 \%)$ & $1(20 \%)$ \\
\hline RF Negative Polyarthritis & $13(36 \%)$ & $4(24 \%)$ & $1(20 \%)$ \\
\hline RF Positive Polyarthritis & $0(0 \%)$ & $0(0 \%)$ & $0(0 \%)$ \\
\hline Psoriatic Arthritis & $2(6 \%)$ & $3(18 \%)$ & $3(60 \%)$ \\
\hline Enthesitis Related Arthritis & $8(22 \%)$ & $1(6 \%)$ & $0(0 \%)$ \\
\hline Unknown & $1(3 \%)$ & $0(0 \%)$ & $0(0 \%)$ \\
\hline Active uveitis at start of therapy & $4(11 \%)$ & $7(41 \%)$ & $2(40 \%)$ \\
\hline Female & $22(61 \%)$ & $12(71 \%)$ & $2(40 \%)$ \\
\hline Age (years) & $13(9-15)$ & $14(11-15)$ & $13(12-16)$ \\
\hline Disease duration (years) & $2(1-5)$ & $6(3-10)$ & $7(6-13)$ \\
\hline Active Joints (71 joints) & $2(1-4)$ & $0(0-2)$ & $0(0-0)$ \\
\hline Limited Joints (71 joints) & $2(1-4)$ & $2(0-4)$ & $0(0-1)$ \\
\hline Physician Global $(0-10 \mathrm{~cm})$ & $2(2-4)$ & $1(0-2)$ & $0(0-0)$ \\
\hline Patient Global $(0-10 \mathrm{~cm})$ & $5(1-7)$ & $2(0-4)$ & $2(0-4)$ \\
\hline Pain VAS $(0-10 \mathrm{~cm})$ & $4(1-7)$ & $4(2-5)$ & $1(0-1)$ \\
\hline CHAQ (0-3) & $1(0-1)$ & $0(0-2)$ & $0(0-1)$ \\
\hline
\end{tabular}

Conclusions: In the UK, etanercept biosimilars are now frequently used as firstline biologics in RA patients. These short-term follow-up data demonstrate in routine clinical care that ETA-B appears to be equivalent to ETA-O in terms of short term effectiveness, drug survival and safety.

Disclosure of Interest: None declared

DOI: 10.1136/annrheumdis-2018-eular.4508

\section{AB0430 SUBJECTIVE ASSESSMENTS OF PATIENTS WITH RHEUMATOID ARTHRITISREPORTED THAT BIO- HOLIDAY THERAPY BROUGHT THEM FINANCIAL AND PSYCHOLOGICAL IMPROVEMENTS}

E. Torikai ${ }^{1}$, D. Suzuki ${ }^{1}$, M. Suzuki ${ }^{2}$, Y. Matsuyama ${ }^{2} .{ }^{1}$ Department of Rheumatology, Iwata city hospital, Iwata; ${ }^{2}$ Department of Orthopaedic surgery, Hamamtsu university school of medicine, Hamamatsu, Japan

Background: At EULAR 2016 and 2017 we reported that it is possible to maintain disease activity, radiographic progression, physical function, and bone metabolism status in rheumatoid arthritis (RA) patients with clinical disease activity index (CDAI) remission using the biologic agents (Bio)-holiday therapy. Currently, in RA therapy, subjective assessment of patients as well as objective assessment of doctors is becoming more important ${ }^{(1)}$. How does the patient think about Bio-holiday therapy?

Objectives: We conducted questionnaire survey in RA patients with CDAI remission who underwent Bio-holiday therapy or Bio-continue therapy to evaluate the benefits of their therapies and to clarify the number of patients concerned about flare-up.

Methods: The first and second survey comprised 9 and 11 questions, respectively; each provided predefined answers. In the first survey, we questioned 85 RA patients in CDAl remission: those treated with any DMARDs. We asked them about the expected elements of RA treatment. In the second survey, we questioned two groups of patients with CDAI remission; those treated with Bio-continue after achieved CDAl remission (BC group: $n=26$ ) and those treated with Bio-holiday therapy after achieved CDAl remission (BH group: $n=28)$. We asked them by a questionnaire what was expected from the treatment effect and how much they felt anxiety about the activity of daily life (ADL) deterioration, RA flare-up and treatment costs.

For Bio-holiday therapy, patients with CDAI remission were treated with golimumab or tocilizumab. Bio was discontinued if they achieved CDAI remission. Patients were treated with Bio within 3 months after falling out of CDAI remission. They could be taken off Bio again when they reached CDAl remission.

Results: In the first survey (figure 1), pain improvement and inexpensive treatment were the most and the second expected treatment effect, respectively. In the second survey (Figure 2), for questions regarding expectation from RA treatment effect, the patients reported that the most beneficial points was pain improvement and the second one was the active daily living without difficulty. Patients in both groups equally recognised reduction in pain and recovery of activities of daily living, which are important for patients with CDAI remission. Interestingly, improvement of emotional depression is the higher in $\mathrm{BH}$ group than in $\mathrm{BC}$ group. For question regarding anxiety, the high medical expense was the most anxious point. Anxiety regarding high medical expenses in $\mathrm{BH}$ group was lower than that in $\mathrm{BC}$ group. Anxiety regarding flare-up was equal to that in $\mathrm{BC}$ group as patients were assured of retreatment with Bio in case of a flare-up.

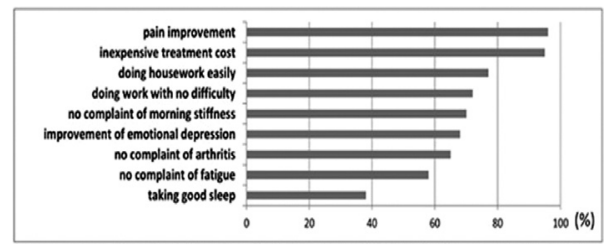

Abstract AB0430 - Figure 1. Questionnaire results of all RA patients with CDAl remission

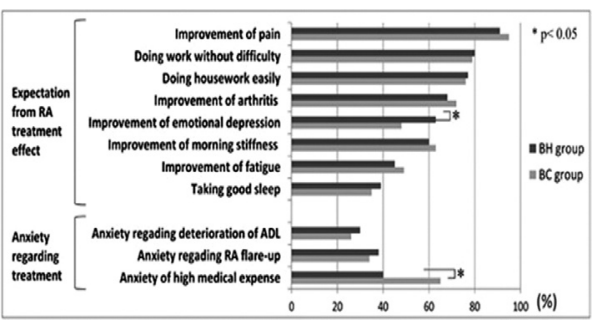

Abstract AB0430 - Figure 2. Questionnaire results of RA patients with CDAI remission who underwent Bio-holiday therapy or Bio-continue therapy

Conclusions: Patients in both groups were equally satisfied with the improvement of their disease activity and progression of ADL. Reduction of the anxiety regarding treatment costs and flare-up in Bio-holiday therapy also helped to improve psychological aspects. Therefore, we recommended Bio-holiday therapy for RA patients with CDAI remission.

\section{REFERENCE:}

[1] Vibeke Strand, et al. J Rheumatol 2015.

Disclosure of Interest: None declared

DOI: 10.1136/annrheumdis-2018-eular.4411

\section{AB0431 EARLIER AGE AT THERAPY INITIATION IS ASSOCIATED WITH BETTER RESPONSE TO TOCILIZUMAB THERAPY IN PATIENTS WITH JUVENILE IDIOPATHIC POLYARTHRITIS}

E. Alexeeva $^{1,2}$, T. Dvoryakovskaya ${ }^{1,2}$, M. Soloshenko $^{1}$, R. Denisova ${ }^{1}$, K. Isaeva ${ }^{1}$, A. Mamutova1', V. Gladkikh ${ }^{3,4}$, A. Moskalev ${ }^{3,4}$. ${ }^{1}$ National Medical Research Center for Children's Health; ${ }^{2}$ Sechenov First Moscow State Medical University (Sechenov University), Moscow, ${ }^{3}$ EOL Labs Itd, Department of Biostatistics; ${ }^{4}$ Institute of Computational Mathematics and Mathematical Geophysics SB RAS, Novosibirsk, Russian Federation

Background: The use of therapy with anti-cytokine biologicals in routine practice has significantly increased the percentage of children showing good response to therapy and reduced the time to achieve pharmacological remission. Nevertheless, the problem related to selecting the optimal drug for a certain patient still remains to be solved.

Objectives: This study was aimed at identifying clinical and laboratory parameters associated with response to tocilizumab (TOC) treatment in patients with RFnegative polyarticular JIA.

Methods: The prospective study to assess TOC efficacy involved 55 patients with RF-negative polyarticular JIA aged 9.42 years (IQR 5.96-13.42), with females (85.5\%) predominating was conducted at the National Medical Research Centre of Children's Health (Moscow). Treatment efficacy was evaluated using the ACRPedi criteria; Wallace's criteria were used to assess whether a patient had reached inactive disease or remission. The potential baseline characteristics associated with treatment response were identified using univariate and multivariate logistic regression analyses. Baseline factors included the clinical, laboratory and anamnestic data. 
Results: TOC therapy showed high efficacy in children with RF-negative polyarticular JIA: $81.8 / 67.3 / 47.3 / 23.6 \%$ of patients reached the ACR30/50/70/90 criteria for the end of follow-up, respectively. The median time of achieving at least $30 \%$ improvement from baseline (ACR30) was 1 months (IQR 1:3).

Univariate analysis showed that earlier age at initiation of Tocilizumab therapy, higher physician's global assessment score using the 100-point Visual Analogue Scale, and longer morning stiffness were the factors associated with reaching ACR90. Younger age at therapy initiation, greater number of swollen joints and joints with limited range of motion, and history of using fewer biologicals are the factors associated with reaching inactive disease and remission. However, multifactorial analysis showed that only earlier age at initiation of TOC therapy was a statistically significant factor associated with reaching the best response to therapy in all the models.

Conclusions: Earlier initiation of TOC therapy is associated with higher chances for reaching ACR90 and pharmacological remission in patients with RF-negative polyarticular JIA. Further studies in larger cohorts are needed to identify the optimal age at therapy initiation.

Disclosure of Interest: E. Alexeeva: None declared, T. Dvoryakovskaya Grant/ research support from: Roche, Pfizer, M. Soloshenko: None declared, R. Denisova: None declared, K. Isaeva: None declared, A. Mamutova: None declared, V. Gladkikh: None declared, A. Moskalev: None declared DOI: 10.1136/annrheumdis-2018-eular.6487

\section{AB0432 BIOLOGIC DMARDS TREATMENT RETENTION IN PATIENTS WITH RHEUMATOID ARTHRITIS ACCORDING TO THE MOSCOW ARTHRITIS REGISTRY (MERA)}

E. Koltsova ${ }^{1}$, E. Zhilyaev ${ }^{2}$, G. Lukina ${ }^{3}$, E. Shmidt ${ }^{4} .{ }^{1}$ Research Institute of the Organization of health and healthcare management, ${ }^{2} \mathrm{CJSC}$ «European Medical Center »; ${ }^{3}$ Moscow Clinical Scientific Center, ${ }^{4}$ City Clinical Hospital 1 named after N.I. Pirogov, Moscow, Russian Federation

Background: Retention on treatment is a good index of efficacy and safety of treatment used in the real clinical practice. These data may be useful to planning the treatment among some years. ${ }^{12}$

Objectives: To compare the drug survival of biological therapies.

Methods: We followed rheumatoid arthritis patients treated with biologics DMARD and registered in MERA 2012-January 2018. All patients had more than one visit in the registry.

Results: We analysed 799 patients (mean age $57,3 \pm 13$, mean diseases duration $15,6 \pm 10,3$ years). The average time until a change of treatment for infliximab was 399 days - the shortest treatment duration. Abatacept (median survival - 2922 days) demonstrated significant superiority over adalimumab (1339 days) $(p<0.001)$, infliximab (399 days) $(p<0.001)$, rituximab (2557 days) $(p=0.004)$ and etanercept ( 1492 days) $(p=0.035)$ when they was used as the first biologic drug. Among second-line therapy, the longest treatment survival has etanercept (3435 days), the shortest - infliximab (212 days).

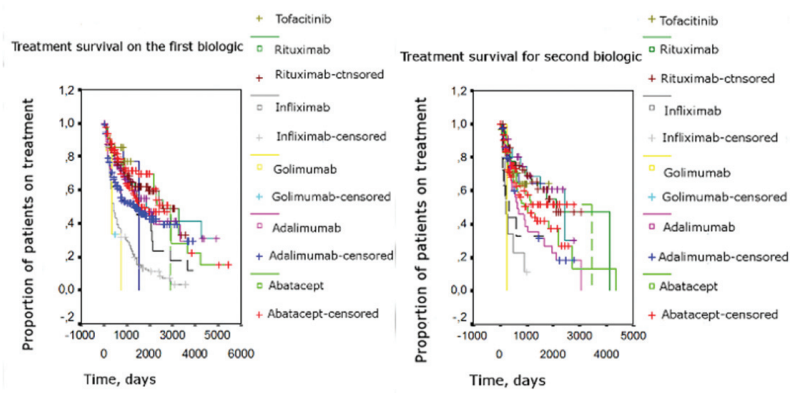

Abstract AB0432 - Figure 1

Conclusions: The results of the trial show the differences in treatment survival of some biologics. It can be reasonable to take these significant differences into consideration by the long-term planning of the biologic treatment of rheumatoid arthritis patients.

\section{REFERENCES:}

[1] Virginia Martinez-Santana, et al. Comparison of drug survival rates for tumor necrosis factor antagonists in rheumatoid arthritis. Patient Prefer Adherence 2013;7:719-727.

[2] Du Pan SM. Arthritis Rheum. Comparison of drug retention rates and causes of drug discontinuation between anti-tumor necrosis factor agents in rheumatoid arthritis 2009
Disclosure of Interest: None declared

DOI: 10.1136/annrheumdis-2018-eular.7173

\section{AB0433 PATIENTS WITH RHEUMATOID ARTHRITIS. REAL- WORLD DATA FROM THE RUSSIAN NORTH-WESTERN BIOLOGICAL TREATMENT COHORT}

E. Vasilenko, R.R. Samigullina, V.I. Mazurov, E.A. Trofimov, I.Z. Gaydukova. North-Western State Medical University named after I.I. Mechnikov, SanktPeterburg, Russian Federation

Background: Biologics are drugs that improved the status of rheumatoid arthritis (RA). At the same time real-world data (RWD) from large cohorts can give some additional information about efficacy and safety of the biological agents.

Objectives: The aim of the study was to analyse the efficacy and safety of biological treatment in large prospective cohort during 102 weeks of treatment.

Methods: The data from 1400 patients on biological treatment from North-Western State Medical University Biological Treatment Cohort Study (St. Petersburg, Russia) were analysed. In final analysis data from 758 patients with RA/EULAR 2010 criteria), were included. Following drugs were used: adalimumab $(n=22)$, certolizumab pegol $(n=62)$, etanercept $(n=64)$, golimumab $(n=21)$ and infliximab $(n=69)$, rituximab $(n=520)$ ). The disease activity index (DAS28) and high-sensitive C-reactive protein (C-RP) were evaluated as markers of RA activity. Side effects were registered during the study.

Results: RA activity, demographic characteristics, and concomitant treatment (including methotrexate, glucocorticoids, NSAIDs, analgesics) at baseline were similar in all the treatment groups ( $p \geq 0.05$ for all the parameters). The faster response was found in golimumab and certolizumab pegol patients ( $p$ and It; 0.01 for difference of DAS28 in golimumab, certolizumab pegol treatment and other treatment groups at week 6), figure 1. After week 12 the similar efficacy of all the TNFa-blockers (figure 1).

RA activity, demographic characteristics, and concomitant treatment (including methotrexate, glucocorticoids, NSAIDs, analgesics) at baseline were similar in all the treatment groups ( $p \geq 0.05$ for all the parameters). The faster response was found in golimumab and certolizumab pegol patients $(p<0.01$ for difference of DAS28 in golimumab, certolizumab pegol treatment and other treatment groups at week 6), figure 1. After week 12 the similar efficacy of all the TNFa-blockers (fig ure 1).C-RP levels were similar in all the treatment groups in all time-points $(p \geq 0.05)$. DAS28 (mean $\pm S D$ ) in RA patients, treated with rituximab, at baseline, and at weeks 24,54 , and 102 was $6.6 \pm 2.4,3.7 \pm 1.7,3.62 \pm 2.1$ and $3.2 \pm 2.05$, respectively; $\mathrm{p} \geq 0.05$ for the differences with all another treatment groups at the same time-points.

The most frequent side-effects were opportunistic infections, OR=1.8 $[95 \% \mathrm{Cl}$ 1.4-2.1]. Risk of infections was higher in patients, receiving monoclonal antibodies to TNF $\alpha$, as compared to other TNF $\alpha$ inhibitors $(p<0.01$ for differences between infliximab/adalimumab/golimumab and etanercept, and $p<0.05$ for differences between infliximab/adalimumab/golimumab and certolizumab pegol).

The risk of cancer in RA patients on biological treatment and in total Russian population (including lymphomas and skin cancer) was comparable: for all the tumours $\mathrm{OR}=0.98[95 \% \mathrm{Cl} 0.76-1.26]$, for lymphomas $\mathrm{OR}=1.23[95 \% \mathrm{Cl} 0.92$ 1.41], for skin cancer $\mathrm{OR}=1.11[0.88-0.36]$.

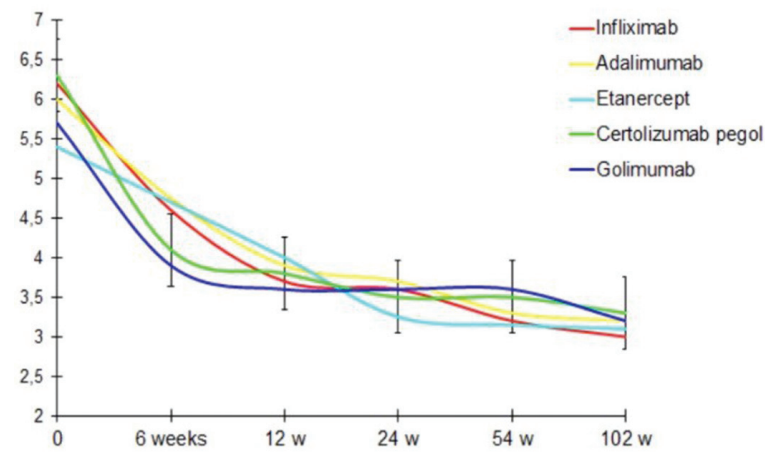

Abstract AB0433 - Figure 1. The dynamics of the disease activity index DAS28 in patients with RA receiving different TNF-a blockers

Conclusions: According to the RWD from the North-Western Biological Treatment Cohort, the efficacy of all the TNF $\alpha$-inhibitors and rituximab in RA treatment 